\title{
Health literacy of common ocular diseases in Nepal
}

\author{
Mohan Krishna Shrestha ${ }^{1 *}$, Christina W Guo ${ }^{2}$, Nhukesh Maharjan', Reeta Gurung ${ }^{1}$ and Sanduk Ruit ${ }^{1}$
}

\begin{abstract}
Background: Poor health literacy is often a key cause of lack of or delayed uptake of health care services. The aim of this study was to assess the health literacy of common ocular diseases, namely cataract, glaucoma, night blindness, trachoma and diabetic retinopathy in Nepal.

Methods: A cross sectional study of 1741 participants randomly selected from non-triaged attendants in the outpatient queue at Tilganga Institute of Ophthalmology, a semi urban general population of Bhaktapur district of Kathmandu Valley and patients attending rural outreach clinics. Participants responded to trained enumerators using verbally administered, semi structured questionnaires on their awareness and knowledge of cataract, glaucoma, diabetic retinopathy, night blindness, and trachoma.

Results: The awareness of cataract across the entire sample was $49.6 \%$, night blindness was $48.3 \%$, diabetic retinopathy was $29 \%$, glaucoma was $21.3 \%$ and trachoma was $6.1 \%$. Patients presenting to rural outreach clinics had poorer awareness of cataract, glaucoma, diabetic retinopathy, night blindness and trachoma compared to those from a semi-urban community and an urban eye hospital $(p<0.05)$, Old age was directly associated with poorer awareness of cataract, glaucoma, night blindness, trachoma and diabetic retinopathy $(p<0.05)$. Female gender was associated with lower awareness of cataract, glaucoma, night blindness and trachoma $(p<0.05)$. Literacy was associated with greater awareness of cataract, glaucoma, diabetic retinopathy, night blindness and trachoma $(p<0.05)$. Higher education was significantly associated with greater awareness of cataract, night blindness and trachoma $(p<0.05)$. Multivariate analysis found that the awareness of common ocular diseases was significantly associated with level of education $(p<0.05)$. Similarly, awareness of cataract, glaucoma, trachoma and night blindness was associated with female gender $(p<0.05)$ whereas awareness of cataract, night blindness, trachoma and diabetic retinopathy was associated with age $(p<0.05)$ but the awareness glaucoma and diabetic retinopathy was associated with camps.
\end{abstract}

Conclusions: Low awareness of common ocular conditions is associated with factors such as female gender, old age, lower levels of education and rural habitation. A would be successful health promotion programs should specifically target health determinants to promote health literacy and to ensure timely utilization of eye care services.

Keywords: Cataract, Diabetic retinopathy, Glaucoma, Health literacy, Nepal, Night blindness, Trachoma

\section{Background}

In 1981, the Nepal Blindness Survey provided the first epidemiological information on the prevalence of blindness in Nepal. The prevalence of blindness in Nepal was estimated to be $0.84 \%$ and was among the poorer in the world [1]. The Rapid Assessment of Avoidable Blindness Survey in 2012 of Nepal found that the prevalence of blindness was $0.35 \%$ [2]. Despite the expansion of

\footnotetext{
* Correspondence: research@tilganga.org

${ }^{1}$ Tilganga Institute of Ophthalmology, PO Box 561, Kathmandu, Nepal

Full list of author information is available at the end of the article
}

eye health services, preventable and correctable ocular conditions such as cataract remain leading causes of blindness in Nepal [3-7].

It has long been recognized that in both developing and developed countries, poor health literacy is a key cause of lack of or delayed uptake of health care services, lack of compliance to treatment and poor followup [8-12]. Health literacy is defined as the ability of an individual to access, understand and use information to promote and maintain good health [13]. It has been suggested that poor ocular health literacy is a key contributor to the dichotomy that exists between disease

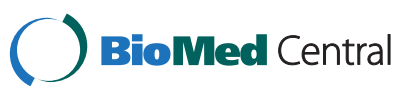


prevalence and service uptake [5,14-16]. In an Indian study, it was found that awareness and knowledge of common ocular conditions, such as cataract, glaucoma, night blindness, trachoma and diabetic retinopathy was very poor [9]. Having heard of the disease was defined as "awareness" and having some understanding of the basic etiology and symptoms of the disease was defined as "knowledge". At present, no comprehensive study on the awareness and knowledge of common ocular conditions exists for the Nepalese population.

Health education and promotion is the one of the most powerful tools to increase the health literacy, as a public health goal, in different settings or localities [17-19]. As Nepal is a developing country, eye health system here is more focused on the curative services rather than promotive and preventive services. It is the best time to assess and explore the situation of the awareness and knowledge of common eye diseases among different groups of people to help the eye health authorities to make and implement a good plan which is both cost effective and efficient in different social and geographic settings in Nepal.

The aim of this study was to investigate the awareness and knowledge of common causes of blindness, namely: cataract, glaucoma, diabetic retinopathy, night blindness and trachoma in a semi-urban community of Kathmandu Valley; patients presenting to an urban eye hospital and; patients presenting to rural outreach clinics (camps). Since health literacy itself is a multi- factorial entity, the study also investigated the relationship between lack of awareness and other risk factors of poor ocular health such as gender, location of habitation, level of education, literacy and age.

\section{Methods}

The cross sectional study was conducted to determine the awareness and knowledge of cataract, glaucoma, night blindness, trachoma and diabetic retinopathy in 1741 respondents over a three month period (March through May in 2009). The sample size was determined by the assumed status of awareness and knowledge of the diseases. Since the status of awareness and knowledge of these conditions are unknown in Nepal, the status of awareness and knowledge figures were derived from studies in India [9]. Night blindness and trachoma were of the lowest awareness and knowledge thus the assumed lowest status of awareness was $20 \%$ in all diseases with allowable error of $20 \%$. Then the minimum sample size was 400 in each group. The study ultimately recruited 1741 participants.

Within each location, respondents were randomly selected including 893 respondents from the general semiurban population of the Bhaktapur district of Kathmandu Valley, 413 respondents from the outpatient queue of an urban eye hospital (Tilganga Institute of Ophthalmology) and 431 respondents presenting to rural outreach clinics. The three groups were selected because they provided respondents from both rural and urban communities. They also represent the groups to which new health promotion measures could be immediately implemented. As free and accessible services are infrequent in rural communities, it is common for many patients who are free of disease symptoms to present themselves at rural outreach clinics. Thus, the sample of patients from four rural outreach clinics in Kathmandu Valley provides a representative sample of the rural community in general. Respondents aged 18 and above years were selected by two processes: (1) the process of simple random sampling using their registration number if they were at the hospital outpatient clinic and rural outreach clinic, or (2) the use of the latest community member list provided by the local government for the semi urban community from the Bhaktapur district of Kathmandu Valley. Questionnaires on awareness and knowledge of cataract, glaucoma, night blindness, trachoma and diabetic retinopathy were designed in English by the Research Department at Tilganga Institute of Ophthalmology, and translated into Nepali using a pragmatic approach to adapt to the target population. All questionnaires were verbally administered by field enumerators who spoke local language and had an understanding of the eye diseases of interest. They were trained and supervised on site by investigators from the research department of Tilganga Institute of Ophthalmology. The same enumerators and investigators were involved at all sites. The pretesting of questionnaires was conducted by enumerators on a similar semi-urban community from a different district of Kathmandu Valley, as well patients from both urban and rural backgrounds at the institute. Respondents demonstrated awareness if they had heard of the eye disease in question. All questions about knowledge were semi- structured. Respondents were asked to "tell" what threat the eye disease posed. The questionnaire contained a list of the possible responses, and the field enumerators marked against the response that most closely corresponded to the respondent's answer.

Collected data was reviewed immediately on site by the enumerators, then centrally at the Tilganga Institute of Ophthalmology. The data was collated and entered into Microsoft Excel 2007 at the Research Department of Tilganga Institute of Ophthalmology. The data were analyzed using Statistical Package for Social Science (SPSS Inc., Chicago, IL, USA) version 11.5. The bivariate (Spearman's Rho test, chi square test and odds ratio) and multivariate analysis was used to determine the relationship between age, gender, rural habitation, literacy and level of education with 
awareness. P values less than 0.05 were considered statistically significant.

The Institutional Review Committee of Tilganga Institute of Ophthalmology reviewed and gave approval to conduct research in the line with the Helsinki Declaration of Medical Ethics.

\section{Results}

\section{Demographic information}

One thousand seven hundred and forty one participants were included in this study. Eight hundred and ninety three (51.29\%) were from the semi-urban communities in Bhaktapur district in Kathmandu Valley, 431 (24.76\%) were from the outpatient queue at the Tilganga Institute of Ophthalmology, an urban eye hospital, and 417 (23.95\%) were selected from rural outreach clinics. Their age ranged from 16 to 89 years and the mean age was 41.5 (SD 17.7) years. The male to female ratio was 1.2 (54.6\% male and $45.4 \%$ female). Thirty three point four percent of respondents were illiterate, defined as no formal schooling (Table 1).

\section{Awareness of common ocular conditions}

Overall awareness was $49.6 \%$ (863) for cataract, $21.3 \%$ (370) for glaucoma, 48.3\% (841) for night blindness, 6.1\% (106) for trachoma and 29\% (504) for diabetic retinopathy (Table 2 Part A).

\section{Age}

Old age was significantly associated with poorer awareness of cataract (Spearman's Rho correlation coefficient $(r)=0.94, p=0.005)$, glaucoma $(r=1.00, p<0.001)$, night blindness $(\mathrm{r}=1.00, \mathrm{p}<0.001)$, trachoma $(\mathrm{r}=0.89, \mathrm{p}=$ $0.019)$ and diabetic retinopathy $(\mathrm{r}=1.00, \mathrm{p}<0.001)$ (Table 2, part C).

\section{Gender}

Females had significantly lower awareness of cataract (odds ratio $=1.77$ (95\% confidence interval $(\mathrm{CI})=1.46-2.14$, $\mathrm{p}<0.001$ ), glaucoma (odds ratio $=1.38(95 \% \mathrm{CI}=1.09$ 1.75), $\mathrm{p}=0.007)$, night blindness (odds ratio $=1.67(95 \%$ $\mathrm{CI}=1.38-2.02), \mathrm{p}<0.001)$, trachoma (odds ratio $=1.67(95 \%$ $\mathrm{CI}=1.10-2.52), \mathrm{p}=0.014)$. The difference in awareness for

Table 1 Summary of demographic of respondents $(n=1741)$

\begin{tabular}{|c|c|c|c|c|}
\hline Description & $\begin{array}{c}\text { Total } \\
\text { Number (\%) }\end{array}$ & $\begin{array}{c}\text { Semi-urban general } \\
\text { Number (\%) }\end{array}$ & $\begin{array}{c}\text { Urban hospital } \\
\text { Number (\%) }\end{array}$ & $\begin{array}{c}\text { Rural outreach } \\
\text { Number (\%) }\end{array}$ \\
\hline \multicolumn{5}{|l|}{ Location } \\
\hline Semi-urban general population & $893(51.3)$ & & & \\
\hline Urban hospital-outpatient clinic & $431(24.8)$ & & & \\
\hline Rural outreach clinics & $417(24.0)$ & & & \\
\hline \multicolumn{5}{|l|}{ Age } \\
\hline$<20$ & $142(8.2)$ & $56(6.3)$ & $56(13.0)$ & $30(7.2)$ \\
\hline 20-29 & $411(23.6)$ & 196(21.9) & 173(40.1) & $42(10.1)$ \\
\hline 30-39 & $323(18.6)$ & 175(19.6) & $100(23.2)$ & $48(11.5)$ \\
\hline $40-49$ & 284(16.3) & 172(19.3) & $51(11.8)$ & $61(14.6)$ \\
\hline 50-59 & 224(12.9) & $121(13.5)$ & $33(7.7)$ & $70(16.8)$ \\
\hline $60-69$ & 197(11.3) & 97(10.9) & $16(3.7)$ & $84(20.1)$ \\
\hline$\geq 70$ & $160(9.2)$ & $76(8.5)$ & $2(0.5)$ & $82(19.7)$ \\
\hline \multicolumn{5}{|l|}{ Gender } \\
\hline Male & $950(54.6)$ & $448(50.2)$ & $92(21.3)$ & $251(60.2)$ \\
\hline Female & $791(45.4)$ & $445(49.8)$ & $339(78.7)$ & 166(39.8) \\
\hline \multicolumn{5}{|l|}{ Level of education } \\
\hline No education & $582(33.4)$ & $315(35.3)$ & $41(9.5)$ & $226(54.2)$ \\
\hline Less than primary & 239(13.7) & $138(51.5)$ & $37(8.6)$ & $64(15.3)$ \\
\hline Primary & 189(10.9) & $92(10.3)$ & 64(14.8) & $33(7.9)$ \\
\hline Secondary & $341(19.6)$ & 144(16.1) & 135(31.3) & $62(14.9)$ \\
\hline Higher secondary & $390(22.4)$ & 204(22.8) & 154(35.7) & $32(7.7)$ \\
\hline \multicolumn{5}{|l|}{ Literacy rate } \\
\hline Illiterate & $582(33.4)$ & $315(35.3)$ & $41(9.5)$ & $226(54.2)$ \\
\hline Literate & $1159(66.6)$ & $578(64.7)$ & 390(90.5) & 191(45.8) \\
\hline
\end{tabular}


Table 2 Association of awareness of cataract, glaucoma, night blindness, trachoma, diabetic retinopathy in relation to age, sex, education, literacy and location $(n=1741)$

\begin{tabular}{|c|c|c|c|c|c|c|}
\hline \multirow[t]{2}{*}{ Variables } & \multirow[t]{2}{*}{ Total number } & \multicolumn{5}{|c|}{ Awareness } \\
\hline & & Cataract & Glaucoma & Night blindness & Trachoma & Diabetic retinopathy \\
\hline \multicolumn{7}{|l|}{ Part A } \\
\hline Grand Total & 1741 & $863(49.6)$ & $370(21.3)$ & $841(48.3)$ & $106(6.1)$ & $504(29.0)$ \\
\hline \multicolumn{7}{|l|}{ Part B: Location ${ }^{\mathrm{a}}$} \\
\hline Semi-urban general population & 893 & $484(54.2)$ & $256(28.7)$ & $473(52.9)$ & $65(7.3)$ & $326(36.5)$ \\
\hline Urban hospital-outpatient clinic & 431 & $237(54.9)$ & $78(18.1)$ & $252(58.5)$ & $36(8.4)$ & 112(25.9) \\
\hline Rural outreach clinics (camps) & 417 & 142(34.1) & $36(8.6)$ & $116(27.8)$ & $5(1.2)$ & $66(15.8)$ \\
\hline \multicolumn{7}{|l|}{ Part C: Age group(years) ${ }^{\text {b }}$} \\
\hline$<20$ & 142 & $84(59.2)$ & $31(21.8)$ & 105(73.9) & $8(5.6)$ & $52(36.6)$ \\
\hline 20-29 & 411 & 253(61.6) & $112(27.3)$ & $271(65.9)$ & $41(10.0)$ & 155(37.7) \\
\hline 30-39 & 323 & $175(54.2)$ & $79(24.5)$ & 157(48.6) & $24(7.4)$ & 108(33.4) \\
\hline $40-49$ & 284 & 136(47.9) & $68(23.9)$ & 137(48.2) & $22(7.7)$ & $83(29.2)$ \\
\hline $50-59$ & 224 & $91(40.6)$ & $42(18.8)$ & 83(37.1) & $7(3.1)$ & $50(22.3)$ \\
\hline $60-69$ & 197 & $63(32.0)$ & $21(10.7)$ & $51(25.9)$ & $2(1.0)$ & $34(17.3)$ \\
\hline$\geq 70$ & 160 & $61(38.1)$ & 17(10.6) & $37(23.1)$ & $2(1.3)$ & $22(13.8)$ \\
\hline \multicolumn{7}{|l|}{ Part D: Gender ${ }^{c}$} \\
\hline Male & 950 & $532(56)$ & $225(23.7)$ & $514(54.1)$ & $70(7.4)$ & $290(30.5)$ \\
\hline Female & 791 & $331(41.8)$ & 145(18.3) & $327(41.3)$ & $36(4.6)$ & $214(27.1)$ \\
\hline \multicolumn{7}{|l|}{ Part E: Education ${ }^{d}$} \\
\hline No education & 582 & $165(28.4)$ & $65(11.2)$ & $141(24.2)$ & $11(1.9)$ & $88(15.1)$ \\
\hline Less than primary & 239 & $118(49.4)$ & 47(19.7) & $101(42.3)$ & $9(3.8)$ & $69(28.9)$ \\
\hline Primary & 189 & $84(44.4)$ & $35(18.5)$ & 73(38.6) & $10(5.3)$ & $35(18.5)$ \\
\hline Secondary & 341 & 193(56.6) & $67(19.6)$ & 190(55.7) & $18(5.3)$ & $95(27.9)$ \\
\hline Higher secondary & 390 & $303(77.7)$ & $156(40.0)$ & $336(86.2)$ & $58(14.9)$ & 217(55.6) \\
\hline \multicolumn{7}{|l|}{ Literacy $^{e}$} \\
\hline Literate & 582 & $165(28.4)$ & $65(11.2)$ & $141(24.2)$ & $11(1.9)$ & $88(15.1)$ \\
\hline Illiterate & 1159 & $698(60.2)$ & $305(26.3)$ & $700(60.4)$ & $95(8.2)$ & 416(35.9) \\
\hline
\end{tabular}

${ }_{\mathrm{a}}^{\mathrm{p}}<0.001$ for cataract, glaucoma, night blindness, trachoma and diabetic retinopathy, Pearson chi-square test.

$\mathrm{b}_{\mathrm{p}}=0.005$ for cataract, $\mathrm{p}<0.001$ for glaucoma, night blindness and diabetic retinopathy and $\mathrm{P}=0.019$ for trachoma, Spearman's rho test.

$c_{p}<0.001$ for cataract and night blindness, $p=0.007$ for glaucoma, $p=0.014$ for trachoma, and $p=0.112$ for diabetic retinopathy, Pearson chi-square test.

$d_{p}=0.037$ for cataract and night blindness, $p=0.188$ for glaucoma and diabetic retinopathy, and $p=0.005$ for trachoma, Spearman's rho test.

$e_{p}<0.001$ for cataract, glaucoma, night blindness, trachoma and diabetic retinopathy, Pearson chi-square test.

diabetic retinopathy between males and females was not significant (odds ratio $=1.19(95 \% \mathrm{CI}=0.96-1.46), \mathrm{p}=0.11)$ (Table 2, Part D).

\section{Location of participants}

Patients presenting at rural outreach clinics had significantly poorer awareness of cataract (odds ratio $=2.32(95 \%$ $\mathrm{CI}=1.84-2.91), \mathrm{p}<0.001)$, glaucoma (odds ratio $=3.57$ (95\% CI $=2.48-5.14), \mathrm{p}<0.001$ ), night blindness (odds ratio $=3.14(95 \% \mathrm{CI}=2.47-3.99), \mathrm{p}<0.001)$, trachoma (odds ratio $=6.80(95 \% \mathrm{CI}=2.75-16.82), \mathrm{p}<0.001)$ and diabetic retinopathy (odds ratio $=2.63(95 \% \mathrm{CI}=1.97$ 3.50), $\mathrm{p}<0.001$ ) compared to patients presenting to urban outpatient clinic at Tilganga Institute of Ophthalmology and the general semi-urban population of Kathmandu valley (Table 2 , part B).

\section{Awareness and level of education}

Illiterate participants (33.43\%) had significantly poorer awareness of all ocular conditions investigated including cataract (odds ratio $=3.83(95 \mathrm{CI}=3.09-4.75), \mathrm{p}<0.001)$, glaucoma (odds ratio $=2.84(95 \% \mathrm{CI}=2.13-3.79), \mathrm{p}<0.001)$, night blindness (odds ratio $=4.78(95 \% \mathrm{CI}=3.82-5.96)$, $\mathrm{p}<0.001)$, trachoma (odds ratio $=4.64(95 \% \mathrm{CI}=2.46$ 8.72), $\mathrm{p}<0.001$ ) and diabetic retinopathy (odds ratio $=3.14$ (95\% CI $=2.43-4.06), \mathrm{p}<0.001$ ).

The level of education of participants and their awareness of the conditions was also investigated. The levels 
of education were divided into three categories: illiterate, those who have basic literacy but less than primary school education, those whose highest level of education was primary, lower secondary or higher secondary or tertiary.

Higher level of education was significantly associated with greater awareness of cataract $(\mathrm{r}=0.90, \mathrm{p}=0.037)$, night blindness $(r=0.90, \mathrm{p}=0.037)$ and trachoma $(\mathrm{r}=0.98$, $\mathrm{p}=0.005$ ). However, the relationship between higher education and awareness of diabetic retinopathy $(r=0.70$, $\mathrm{p}=0.188)$ and glaucoma $(\mathrm{r}=0.70, \mathrm{p}=0.188)$ were not significant (Table 2, Part E).

Multiple correlations showed that the awareness on female gender is significantly associated with cataract $(\mathrm{r}=-0.128, \mathrm{p}=0.000)$, glaucoma $(\mathrm{r}=-0.065, \mathrm{p}=0.008)$, trachoma $(\mathrm{r}=-0.060, \mathrm{p}=0.012)$ and night blindness $(\mathrm{r}=-0.115, \quad \mathrm{p}=0.000)$ except diabetic retinopathy ( $\mathrm{r}=-0.023, \mathrm{p}=0.198)$. The awareness is significantly associated with cataract $(\mathrm{r}=-0.142, \mathrm{p}=0.000)$, trachoma $(\mathrm{r}=-0.053, \mathrm{p}=0.025)$, night blindness $(\mathrm{r}=-0.23$, $\mathrm{p}=0.000)$ and diabetic retinopathy $(\mathrm{r}=-0.109, \mathrm{p}=0.000)$ expect glaucoma $(r=-0.042, p=0.060)$ by ageing of population. The awareness is significantly associated with cataract $(\mathrm{r}=0.352, \mathrm{p}=0.000)$, glaucoma $(\mathrm{r}=0.216, \mathrm{p}=0.000)$, trachoma $(\mathrm{r}=0.155, \mathrm{p}=0.000)$, night blindness $(\mathrm{r}=0.420$, $\mathrm{p}=0.000)$ and diabetic retinopathy $(\mathrm{r}=0.265, \mathrm{p}=0.000)$ by higher education level. Whereas the awareness of common ocular diseases is significantly associated with glaucoma $(\mathrm{r}=-0.151, \mathrm{p}=0.000)$ and diabetic retinopathy $(\mathrm{r}=-0.142, \mathrm{p}=0.000)$ with rural outreach clinics (camps) but there is no association with cataract $(r=-0.028$, $\mathrm{p}=0.147)$, trachoma $(\mathrm{r}=-0.014, \mathrm{p}=0.304)$ and night blindness $(\mathrm{r}=0.008, \mathrm{p}=0.379)$ (Table 3$)$.

\section{Source of information}

The survey also investigated the common sources of information for awareness and knowledge of common ocular conditions. The Television and print media such as magazines, posters and newspapers, were the source of information in $52 \%$ of cases. Twenty four point nine percent of respondents derived their awareness and knowledge of common ocular conditions from family, relatives and friends who suffer from the condition, while $9.4 \%$ respondents derived their information from family, relatives and friends who do not suffer from the conditions (9.4\%). Health care workers were the source of awareness in $3.3 \%$ and outreach eye clinics were the source of information in $3.1 \%$ of cases (Table 4 ).

\section{Discussion}

This study identified a number of factors associated with lower awareness of common ocular conditions in Nepal, where blindness due to treatable conditions remains high despite increasing efforts to improve eye health. The factors examined were age, gender, literacy, level of education and location of habitation.

Cataract is the principal cause of blindness in Nepal, followed by glaucoma and diabetic retinopathy and trachoma [20-22]. The awareness of ocular conditions correlated with the prevalence of these conditions with the exception of night blindness. The high level of awareness and low prevalence of night blindness is directly related to the Nepal National Vitamin A Program which is a six month yearly campaign that delivers high dose vitamin A to 6 to 60 months old children in 42 of the 75 districts in Nepal [23].

In Nepal, 69\% of blind people are females [1]. However, there is not a majority of females to males in the Nepalese population. Also, this disparity is not accounted for by longer female life expectancy ( 0.88 males to $1 \mathrm{fe}$ male in those over the age of 65 years) [24]. Females account for $63.8 \%$ of cataract blindness because they do not receive treatment at the same rate as men [1]. It is estimated that cataract blindness would be reduced by $12.5 \%$ in developing countries if women received cataract surgery at the same rate as men [25]. Given the significant difference in level of awareness of common ocular conditions between males and females, it is likely that low level of awareness plays an important role. Potential causes for this include the fact that only $24 \%$ of females in Nepal are literate as opposed to $52 \%$ of males. Females are also more likely to live in a rural location and have lower income $[24,26,27]$. All these factors reduce access to health education, and ultimately, affect health seeking behaviour. Any programs aimed at improving health literacy must specifically address gender specific barriers. Programs aimed at

Table 3 Association of awareness of cataract, glaucoma, night blindness, trachoma, diabetic retinopathy in relation to age, sex, education, literacy and location by multiple correlation analysis

\begin{tabular}{|c|c|c|c|c|c|c|c|c|c|c|}
\hline \multirow[t]{2}{*}{ Variables } & \multicolumn{2}{|c|}{ Cataract } & \multicolumn{2}{|c|}{ Glaucoma } & \multicolumn{2}{|c|}{ Trachoma } & \multicolumn{2}{|c|}{ Night blindness } & \multicolumn{2}{|c|}{ Diabetic retinopathy } \\
\hline & $r$ & $p$ value & $r$ & $p$ value & $r$ & $p$ value & $\mathbf{r}$ & $p$ value & $\mathbf{r}$ & $p$ value \\
\hline Gender & -0.128 & 0.000 & -0.065 & 0.008 & -0.060 & 0.012 & -0.115 & 0.000 & -0.023 & 0.198 \\
\hline Age & -0.142 & 0.000 & -0.042 & 0.060 & -0.053 & 0.025 & -0.230 & 0.000 & -0.109 & 0.000 \\
\hline Education & 0.352 & 0.000 & 0.216 & 0.000 & 0.155 & 0.000 & 0.420 & 0.000 & 0.265 & 0.000 \\
\hline Location & -0.028 & 0.147 & -0.151 & 0.000 & -0.014 & 0.304 & 0.008 & 0.379 & -0.142 & 0.000 \\
\hline
\end{tabular}


Table 4 Source of information for common ocular problems

\begin{tabular}{|c|c|c|c|c|c|c|c|c|c|c|c|c|}
\hline \multirow[t]{2}{*}{ Description } & \multicolumn{2}{|c|}{ Cataract } & \multicolumn{2}{|c|}{ Glaucoma } & \multicolumn{2}{|c|}{$\begin{array}{c}\text { Night } \\
\text { blindness }\end{array}$} & \multicolumn{2}{|c|}{ Trachoma } & \multicolumn{2}{|c|}{$\begin{array}{l}\text { Diabetic } \\
\text { retinopathy }\end{array}$} & \multicolumn{2}{|c|}{ Total } \\
\hline & $\mathrm{N}^{*}$ & $\% * *$ & $\mathrm{~N}^{*}$ & $\% * *$ & $\mathrm{~N}^{*}$ & $\% * *$ & $\mathrm{~N}^{*}$ & $\% * *$ & $\mathbf{N}^{*}$ & $\% * *$ & $\mathrm{~N}^{*}$ & $\% * *$ \\
\hline Television, print media & 395 & 47.9 & 193 & 52.2 & 486 & 58.8 & 74 & 69.8 & 220 & 43.7 & 1368 & 52 \\
\hline Family/friend/relative who suffer from condition & 249 & 30.2 & 82 & 22.2 & 140 & 16.9 & 9 & 8.5 & 174 & 34.5 & 654 & 24.9 \\
\hline Family/friend/relative who do not suffer from condition & 73 & 8.9 & 34 & 9.2 & 77 & 9.3 & 9 & 8.5 & 54 & 10.7 & 247 & 9.4 \\
\hline Eye camp & 28 & 3.4 & 17 & 4.6 & 25 & 3 & 1 & 0.9 & 10 & 2 & 81 & 3.1 \\
\hline Health care workers & 36 & 4.4 & 21 & 5.7 & 10 & 1.2 & 2 & 1.9 & 17 & 3.4 & 86 & 3.3 \\
\hline Others & 43 & 5.2 & 23 & 6.2 & 89 & 10.8 & 11 & 10.4 & 29 & 5.8 & 195 & 7.4 \\
\hline Total & 824 & 100 & 370 & 100 & 827 & 100 & 106 & 100 & 504 & 100 & 2631 & 100 \\
\hline
\end{tabular}

$\mathrm{N}^{*}=$ Number, $\%{ }^{* *}=$ Percent.

improving other determinants such as poor literacy should also be gender-sensitive.

The highest rate of blindness in Nepal is for those who are over 70 years of age where prevalence is over $10.6 \%$ [28]. Even in developed countries, the risk of blindness is ten times higher in those over 65 than for younger individuals $[29,30]$. There are many causes for the under-utilization of services in the elderly. For example, the elderly are more likely to associate decline in vision with natural aging, less likely to present for surveillance and monitoring, more conservative in the uptake of procedures, less compliant with medications and follow-up [31-33]. This may be related to the fact that literacy rates decline with age in both males and females, and urban and rural communities. For example, literacy amongst $10-14$ year olds is $86 \%$ for males and $83 \%$ for females compared to the literacy rate of $34 \%$ for older males and 3\% for older females [34]. The Elderly are also more likely to live in rural areas [35]. Hence, there is a need for culturally secure educational programs targeted at the elderly.

Eighty percent of the Nepalese population and ninety percent of country's blind population live in rural areas. Numerous studies from developed and developing countries have demonstrated under-utilization of services in rural areas [36-40]. With the increase in free rural outreach services, it is proposed that a lack of education about common eye diseases and their management is a major contributor to the current roadblock in service utilization. Despite the fact that rural outreach clinics rely on self-presentation, this study showed that awareness of common ocular diseases is significantly lower in this group when compared to the general population in semi urban communities, as well as those who present to urban tertiary eye care centre. This may be attributed to the fact that tools such as print and electronic media, which are the source of information in $52 \%$ of cases, are less readily available. Also, the significant disparity in literacy rate between urban (literacy rate of 64\%) and rural (literacy rate of $34 \%$ ) communities may preclude the use of such sources [34]. Further, many patients present despite little awareness of eye diseases because outreach clinics are one of the few free health services available to rural communities and the frequency of service provision is low. However, without adequate awareness and knowledge, the initiative to present to outreach clinics may not translate to acceptance of treatments, such as cataract surgery, or timely presentation to services when they are not free and easily accessible [41]. In fact, one study showed that even when offered free transport and free surgery, the utilization of cataract surgery in parts of rural Nepal was as low as 60\% [16]. Therefore, education about the early warning signs of common ocular conditions, the benefits of timely management, and its possible outcomes would be an important addition to current rural outreach services.

Illiteracy is generally associated with lack of disease awareness $[13,42,43]$. Forty three percent of the Nepalese population is illiterate. Fourteen percent of males and $18 \%$ of females have not attended primary school. Fifty four percent of males and 59\% females have not attended high school. Female, old age, rural habitation and lower socio-economic class are all risk factors for illiteracy [34]. This is the same groups who carries the highest burden of disease and have the least capacity to access care. Higher level of education beyond simple literacy is associated with better awareness and knowledge of common ocular conditions when compared to those with basic literacy. This may be confounded by other factors such as higher socio-economic background and urban habitation. In summary, it is vital that future health promotion campaigns need to expand beyond traditional means of printed media to make them accessible to illiterate populations who carry high disease burdens.

Multivariate analysis revealed that the awareness of common ocular diseases namely cataract glaucoma, trachoma, night blindness and diabetic retinopathy was 
significantly associated with level of education $(\mathrm{p}=<0.05)$. Similarly, association was found in female gender, age and location of the participants where some diseases had association with common ocular diseases and some were not. Except diabetic retinopathy $(p=0.198)$, the awareness of common ocular diseases had significant association with female gender $(p=<0.05)$. The awareness of cataract, trachoma, night blindness and diabetic retinopathy had significant association with age $(\mathrm{p}<0.05)$. Glaucoma and diabetic retinopathy were significant association with location $(\mathrm{p}<0.05)$ but other three ocular conditions like cataract, trachoma and night blindness were not associated with rural outreach camps.

There are some limitations to this study. Firstly, two of the three cohorts (approximate $48.71 \%$ of respondents) are already presenting for care either to an urban eye hospital clinic or to a rural outreach clinic, thus, many already demonstrate some awareness of ocular conditions. However, presentation does not necessarily equate to knowledge and awareness, which are essential for identification of early warning signs of disease, compliance to treatment and follow-up. Further, it is common for the majority of the population from a community to present for check-up by the outreach clinics even in the absence of disease or symptom because the service is free and accessible. Therefore, this group offers a relatively representative sample of a rural community. Evidently, there exists much scope for more comprehensive studies on awareness and knowledge of ocular diseases in those from rural communities who have not presented to care, but the recruitment of respondents may be difficult. It is also important to note that while this study examined the relationship between individual determinants of health literacy, it has been alluded to in the discussion that many of these factors co-exist. Therefore, future work is needed to determine the complex interplay between these factors and their collective impact on health literacy and outcome.

\section{Conclusions}

Whilst some progress has been made in the reduction of blindness in Nepal, further improvements necessitate an increase in health literacy of the community. This study shows that even at the sentinel stages of awareness and knowledge, factors such as female gender, old age, illiteracy, lower level of education and rural habitation act as major impediments. Additionally, these factors impacting on health literacy tend to occur simultaneously in the same individuals and producing compounding effects. Strategic actions targeted at these factors are essential in the development of programs that can holistically address all the barriers to the improvement of ocular health.
Competing interests

The authors declare that they have no competing interests.

\section{Authors' contributions}

MKS contributed to the design of the study, its implementation and preparation of the manuscript. CWG contributed to the analysis of data, preparation and revision of the manuscript. NM contributed to the collection and analysis of data. RG and SR contributed to the design of the study and preparation of the manuscript. All authors read and approved the final manuscript.

\section{Acknowledgements and funding}

We would like to acknowledge the Fred Hollows Foundation (FHF) for the financial support. We also like to thank Dr. Andreas Muller, Research Coordinator of FHF, Mr. Todd Ritter, Program Coordinator of FHF, Dr. Anil Subedi, Partnership Manger of FHF, all participants and staffs of Tilganga Institute of Ophthalmology for their contributions to the success of this research work.

\section{Author details}

${ }^{1}$ Tilganga Institute of Ophthalmology, PO Box 561, Kathmandu, Nepal. 2University of Melbourne, Parkville, Victoria 3052, Australia.

Received: 20 March 2013 Accepted: 3 January 2014

Published: 8 January 2014

\section{References}

1. Brilliant LB, Pokhrel RP, Grasset NC, Lepkowski JM, Kolstad A, Hawks W, Pararajasegaram R, Brilliant GE, Gilbert S, Shrestha SR, et al: Epidemiology of blindness in Nepal. Bull World Health Organ 1985, 63(2):375-386.

2. Nepal Netra Jyoti Sangh: The epidemiology of blindness in Nepal. Kathmandu Nepal: Netra Jyoti Sangh; 2012.

3. Rahmani B, Tielsch JM, Katz J, Gottsch J, Quigley H, Javitt J, Sommer A: The cause-specific prevalence of visual impairment in an urban population. The Baltimore Eye Survey. Ophthalmol 1996, 103(11):1721-1726.

4. Rizyal A, Karmacharya PC, Koirala S: Profile of blindness in Nepal: a hospital based study. Nepal Med College J 2005, 7(1):54-57.

5. Thapa SS, Berg RV, Khanal S, Paudyal I, Pandey P, Maharjan N, Twayna SN, Paudyal G, Gurung R, Ruit S, et al: Prevalence of visual impairment, cataract surgery and awareness of cataract and glaucoma in Bhaktapur district of Nepal: The Bhaktapur Glaucoma Study. BMC Ophthalmol 2011, 11(1):2.

6. Khatry SK, West KP Jr, Katz J, LeClerq SC, Pradhan EK, Wu LS, Thapa MD, Pokhrel RP: Epidemiology of xerophthalmia in Nepal. A pattern of household poverty, childhood illness, and mortality. The Sarlahi Study Group. Arch Ophthalmol 1995, 113(4):425-429.

7. Sapkota YD, Sunuwar M, Naito T, Akura J, Adhikari HK: The prevalence of blindness and cataract surgery in rautahat district, Nepal. Ophthalmic Epidemiol 2010, 17(2):82-89.

8. Attebo K, Mitchell $P$, Cumming R, Smith W: Knowledge and beliefs about common eye diseases. Aust N Z J Ophthalmol 1997, 25(4):283-287.

9. Dandona R, Dandona L, John RK, McCarty CA, Rao GN: Awareness of eye diseases in an urban population in southern India. Bull World Health Organ 2001, 79(2):96-102.

10. Livingston PM, Lee SE, De Paola C, Carson CA, Guest CS, Taylor HR: Knowledge of glaucoma, and its relationship to self-care practices, in a population sample. Aust N Z J Ophthalmol 1995, 23(1):37-41.

11. Livingston PM, McCarty CA, Taylor HR: Knowledge, attitudes, and self care practices associated with age related eye disease in Australia. Brit J Ophthalmol 1998, 82(7):780-785.

12. Javitt JC: Preventing blindness in Americans: The need for eye health education. Surv Ophthalmol 1995, 40(1):41-44.

13. 7th Global Conference on Health Promotion: track themes 2: Health literacy and health behaviour. http://www.who.int/healthpromotion/ conferences/7gchp/track2/en/index.html

14. Sapkota YD, Pokharel GP, Dulal S, Byanju RN, Maharjan IM: Barriers to up take cataract surgery in Gandaki Zone, Nepal. Kathmandu Univ Med J (KUMJ) 2004, 2(2):103-112. 
15. Sapkota YD, Pokharel GP, Nirmalan PK, Dulal S, Maharjan IM, Prakash K: Prevalence of blindness and cataract surgery in Gandaki Zone, Nepal. Brit J Ophthalmol 2006, 90(4):411-416.

16. Snellingen T, Shrestha BR, Gharti MP, Shrestha JK, Upadhyay MP, Pokhrel RP: Socioeconomic barriers to cataract surgery in Nepal: the south Asian cataract management study. Brit J Ophthalmol 1998, 82(12):1424-1428.

17. Nutbeam D: Health literacy as a public health goal: a challenge for comptemporary health education and strategies into the 21 st century. Health Prom Int 2000, 15(3):259-267. 15.

18. Shores NJ, Maida I, Soriano V, Nunez M: Sexual transmission is associated with spontaneous HCV clearance in HIV-infected patients. J Hepatol 2008, 49(3):323-328.

19. Noertjojo K, Maberley D, Bassett K, Courtright P: Awareness of eye diseases and risk factors: identifying needs for health education and promotion in Canada. Canad J Ophthalmol 2006, 41(5):617-623.

20. Editorial: Cataract - a leading cause of blindness. J Nepal Med Assoc 2007, 46(167):I-II.

21. Thapa SS, Berg RVD, Khanal S, Paudyal I, Pandey P, Maharjan N, Twyana SN, Paudyal G, Gurung R, Ruit S, et al: Prevalence of visual impairment, cataract surgery and awareness of cataract and glaucoma in Bhaktapur district of Nepal: The Bhaktapur Glaucoma Study. BMC Ophthalmol 2011, 11:1.

22. Nepal facts and figures. http://www.hollows.org/nepal/Facts/

23. Gorstein J, Shreshtra RK, Pandey S, Adhikari RK, Pradhan A: Current status of vitamin a deficiency and the National vitamin a control program in Nepal: results of the 1998 National micronutrient status survey. Asia Pacif J Clin Nutrit 2003, 12(1):96-103.

24. Abou-Gareeb I, Lewallen S, Bassett K, Courtright P: Gender and blindness: a meta-analysis of population-based prevalence surveys. Ophthal Epidemiol 2001, 8(1):39-56

25. Lewallen S, Courtright P: Gender and use of cataract surgical services in developing countries. Bull World Health Organ 2002, 80(4):300-303.

26. Balarajan Y, Selvaraj S, Subramanian SV: Health care and equity in India. Lancet 2011, 377(9764):505-515.

27. Bornemisza O, Ranson MK, Poletti TM, Sondorp E: Promoting health equity in conflict-affected fragile states. Soc Sci Med 2010, 70(1):80-88.

28. Asian Journal of Ophthalmology: Blindness in Asia - The Facts. vol.4th editionSingapore; 2002:11-13.

29. Pizzarello LD: The dimensions of the problem of eye disease among the elderly. Ophthalmology 1987, 94(9):1191-1195.

30. Singh MM, Murthy GVS, Venkatraman R, Rao SP, Nayar S: A study of ocular morbidity among elderly population in a rural area of central India. Ind J Ophthalmol 1997, 45(1):61-65.

31. Brundtland $\mathrm{GH}$ : Endorsement of the global initiative vision 2020: the right to sight. J Comm Eye Health 1999, 12:16.

32. Wormald R: Delivery of eye care to the elderly: practical considerations. Comm Eye Health 1999, 12:6-7.

33. Pradhan S, Mughal N, Mahomed I: Self-reported eye disease in elderly South Asian subjects from an inner city cluster in Bradford: a small-scale study to investigate knowledge and awareness of ocular disease. Eye 2000, 14(4):620-624.

34. Llteracy and education literacy rates. http://cbs.gov.np/wp-content/ uploads/2012/02/Statistical_Report_Vol1.pdf

35. Demographic characteristics. http://cbs.gov.np/wp-content/uploads/2012/ 02/Statistical_Report_Vol1.pdf

36. Chandrashekhar TS, Bhat HV, Pai RP, Nair SK: Coverage, utilization and barriers to cataract surgical services in rural South India: results from a population-based study. Public health 2007, 121(2):130-136.

37. $\mathrm{Ng} \mathrm{JQ}$, Morlet N, Semmens JB: Socioeconomic and rural differences for cataract surgery in Western Australia. Clin Exper Ophthalmol 2006, 34(4):317-323

38. Zhou JB, Guan HJ, Qu J, Yang XJ, Peng D, Gu HY: A study on the awareness of cataract disease and treatment options in patients who need surgery in a rural area of Eastern China. Eur J Ophthalmol 2008, 18(4):544-550.

39. Du Toit R, Ramke J, Naduvilath T, Brian G: Awareness and use of eye care services in Fiji. Ophthal Epidemiol 2006, 13(5):309-320.

40. Krishnaiah S, Kovai V, Srinivas M, Shamanna BR, Rao GN, Thomas R: Awareness of glaucoma in the rural population of Southern India. Ind J Ophthalmol 2005, 53(3):205-208.
41. Brilliant GE, Lepkowski JM, Zurita B, Thulasiraj RD: Social determinants of cataract surgery utilization in South India. Archives of Ophthalmology 1991, 109(4):584-589.

42. Kickbusch IS: Health literacy: addressing the health and education divide. Health Promotion International 2001, 16(3):289-297.

43. Brilliant GE, Brilliant LB: Using social epidemiology to understand who stays blind and who gets operated for cataract in a rural setting. Soc Sci Med 1985, 21(5):553-558.

doi:10.1186/1471-2415-14-2

Cite this article as: Shrestha et al:: Health literacy of common ocular diseases in Nepal. BMC Ophthalmology 2014 14:2.

\section{Submit your next manuscript to BioMed Central and take full advantage of:}

- Convenient online submission

- Thorough peer review

- No space constraints or color figure charges

- Immediate publication on acceptance

- Inclusion in PubMed, CAS, Scopus and Google Scholar

- Research which is freely available for redistribution

Submit your manuscript at www.biomedcentral.com/submit
C Biomed Central 